International

Medical Publisher

http://imedicalpublisher.com

\title{
Incidence and Factors Associated with Death for Tetanus in Adults
}

\section{Roberta Andrade Beltrão', Clarissa Mourão Pinho², Evelyn Maria Braga Quirino², Ana Catarina de Melo Araújo ${ }^{3}$, Sara Larissa de Melo Araújo ${ }^{4}$, Aline Beatriz dos Santos Silva ${ }^{5}$ Maria Beatriz Araújo Silva ${ }^{6}$, Demócrito de Barros Miranda Filho ${ }^{7}$, Maria Sandra Andrade 8}

\section{Abstract}

Background: Tetanus has a worldwide distribution and high lethality. The goal of this study was to characterize the tetanus cases confirmed in Pernambuco and identify factors associated with death in these patients.

Methods and Findings: Cross-sectional, with internal comparison groups. For data analysis we used the chi-square test and Pearson estimated the odds ratios and their respective confidence intervals at 95\%. Multivariate analysis was applied to multiple logistic regression. The incidence of tetanus ranged between 0.65 and 2.79 cases per 100,000 inhabitants with higher involvement of adults, male and city population. Only $13.8 \%$ had received the vaccine and $23.4 \%$ received it as prophylaxis. The average mortality rate was $20.4 \%$. In multivariate analysis, presented neck stiffness as a symptom ( $p=0.029)$, which was associated with increased mortality.

Conclusions: There is a need for greater investment in the prevention of the disease, both in immunization coverage and in the application of prophylaxis. Despite the hospitalization guarantee with proper care, there was an increase in tetanus mortality, suggesting
1 Nurse. Specialist in public health by the multiprofessional residency program in public health of the Oswaldo Cruz Foundation*

2 Nurse. Master student of the Associate Program of Nursing PostGraduation, PSUP*

3 Nurse. Doctorate student at Associate Program of Nursing PostGraduation, PSUP*.

4 Nurse. Master student of the PostGraduation of Health and Biological Sciences of Federal University of Vale do São Franscisco**.

5 Nurse. Master student of the PostGraduation of Public Health Program, PSUP*.

6 Nurse. Doctor in Parasite Biology. Professor, PSUP*

7 Doctor. PhD in Infectious and Parasitic Diseases. Professor of Associate Program of Nursing Post-Graduation PSUP, *.

8 Nurse. Doctor in Health Science. Professor of Associate Program of Nursing Post-Graduation, PSUP*.

*: Recife, Pernambuco, Brazil.

**: Petrolina, Pernambuco, Brazil.

PSUP: University of Pernambuco/State University of Paraíba

Contact information:

Roberta Andrade Beltrão.

Address: Faculdade de Enfermagem Nossa Senhora das Graças, Universidade de Pernambuco. Rua Arnóbio Marques, $n^{\circ} 310$, Santo Amaro, Recife-PE, Brasil. CEP: $50100-130$

Tel: +55 81 99668-9388.

झ beltrao.roberta@gmail.com 
that more specific studies should be conducted to investigate what may have influenced this change. Special attention should be offered to cases that presented neck stiffness as a symptom, because these groups have a higher chance of progressing to death.

\section{Keywords}

Tetanus; Lethality;

Epidemiologic Studies.

\section{Introduction}

Tetanus is a potentially severe disease, with high lethality. The analysis done in 178 countries about tetanus's incidence related the occurrence of 9.836 cases of the disease, being the highest incidence on the African continent (4.607 cases/year) and the lower on Europe (181 cases/year). The American region the second lower incidence, presenting 529 cases/year [1, 2].

Brazil is still responsible for the major tetanus's cases in the American continent, even though, in the period between 2001 and 2011, the country had a reduction of 44 per cent in number of cases of the disease, meaning that in 2001 Brazil registered a total of 578 cases/year and in 2011 were registered 327 cases/year. The highest proportion of cases in the country, approximately a third, occurs in the Northeast region. The state of Pernambuco had a considerable piece of those cases, and in 2004 was responsible for 15 per cent of the region's cases. The lethality in the country in the period between 2001 and 2011 occurred, an average of 30 per cent of the cases, being considered high, when compared with developed countries, which register lethality between 10 per cent and 17 [3, 4].

In a broad way, the developed countries had a significant decrease in the number of cases of tetanus, but the disease's endemic situation persists with lethality reaching up to 50 per cent. Even with a high tax of lethality registered, studies show that theses taxes may be considerably reduced in places where intensive specific care is available $[1,4]$.

It's important to emphasize that tetanus is a disease that can be controlled through immunization.
But, while this goal isn't achieved, the quality of the treatment is indispensable to reduce lethality, being associated to the arrangement of physical installation and equipments, besides an experienced group and the adoption of assistance protocols which allow an intensive and integral care [4, 5].

For such, it's necessary an early diagnosis and implementing therapeutic measures to guarantee the quality and the agility of the treatment. The tetanus's diagnosis is purely clinical, don't need to wait for laboratorial results, however, the health professional, mainly in basic care, needs to be aware of potentially suspicious clinical history or symptomatology. It is recommended to guarantee assistance in an ICU environment with ward to complications and progress of the severe form of the disease [6].

The knowledge of factors that influence in the aggravation of the clinical state have great relevance to the realization of an opportune and more directed assistance, with a more rigorous regarding the patient's evolution. In this context, this study describes incidence and lethality of tetanus's cases in Pernambuco between 2007 and 2015 and identify associated with death.

\section{Methods}

An cross section observational study, with a descriptive and analytical approach, fulfilled through secondary data of accidental tetanus's cases, on residents of the state of Pernambuco, which occurred in the period of 2007 and 2015 and were registered in the Surveillance System of tetanus. 
To verify the associations with death, we tested sociodemographic, clinical, epidemiologic and vaccination status. The favorable and unfavorable closure of the case was considered as a dependent variable.

In the analysis of the characteristics related to the injured, were presented the frequency distribution to the variables. In the analysis of the association between the tetanus case closure and the characteristics of the case, it was applied the Chi-Square Pearson's test and the estimated Odds Ratio. In the analysis, it was considered the tests confidence intervals level of $95 \%$. In the multivariate analysis, it was applied a multiple logistic regression, having as a criterion of entrance a significance of $20 \%$ (p $<0.20)$ and as a criterion of permanence a significance of $10 \%(p<0.10)$. The data collected were tabulated and processed using the software Stata version 12.0 .

The present study was approved in 27/07/2016 by the Ethics Committee of the Aggeu Magalhães Research Center, under CAAE 56172316.4.

\section{Results}

In Pernambuco, 137 cases of accidental tetanus were reported in the period between 2007 and 2015. The incidence of the disease varied between 0.65 and 2.79 cases per 100.000 habitants, with a medium reduction of 0.21 new cases per year (Figure 1).

From the cases confirmed, 125 (91.2\%) had more than 20 years old, and those, a number higher than $70 \%$ were male, black and resided in the urban area (Table 1).

The most registered clinical manifestations were the trismus in 117 (85.4\%) of the cases; 93 (67.9\%) the spasms; 60 (43.8\%) neck stiffness; and 54 (39.4\%) the member's stiffness. In 73 (53.3\%) cases were related other symptoms, and from those, $42.5 \%(31 / 73)$ were muscle contracture related issues.

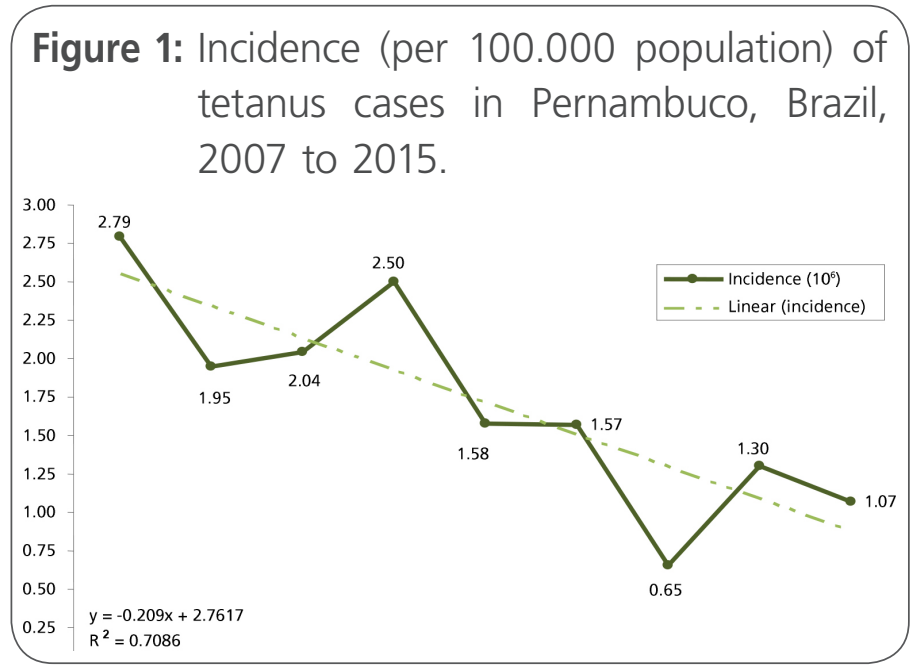

Table 1. Demographic profile of accidental tetanus cases confirmed $(\mathrm{N}=137)$ in Pernambuco, Brazil, 2007 to 2015.

\begin{tabular}{|c|c|c|}
\hline \multirow{2}{*}{ Characteristics } & \multicolumn{2}{|c|}{ Cases } \\
\hline & Number & $\%$ \\
\hline \multicolumn{3}{|l|}{ Age Range } \\
\hline$>20$ & 12 & 8,8 \\
\hline $20-39$ & 30 & 21.9 \\
\hline $40-59$ & 61 & 44.5 \\
\hline$\geq 60$ & 34 & 24.8 \\
\hline \multicolumn{3}{|l|}{ Sex } \\
\hline Male & 118 & 86.1 \\
\hline Female & 19 & 13.9 \\
\hline \multicolumn{3}{|l|}{ Skin Color } \\
\hline White & 23 & 16.8 \\
\hline Brown & 86 & 62.8 \\
\hline Black & 13 & 9.5 \\
\hline Not informed & 15 & 11.0 \\
\hline \multicolumn{3}{|l|}{ Area of residence } \\
\hline Urban & 118 & 86.1 \\
\hline Rural & 14 & 10.2 \\
\hline Peri-urban & 2 & 1.5 \\
\hline Not informed & 3 & 2.2 \\
\hline
\end{tabular}


The most frequent way of contamination with Clostridium tetani was puncture wound. The causes described as others that correspond to 24 (17.5\%) were related to dental extraction (3), ulcers (3), blunt injuries (3), cut (1), traumatic amputation (1), exposed fracture (1), motorcycle accident (1), fireworks accident (1), dog's scratch (1) and injuries described in an incomplete/unspecific way (9). Note that part of the described wounds suggests the necessity of hospital care. The injuries occurred more commonly in superior and inferior members (83.2\%). The injured vaccine situation was unknown in $43 \%$ of the cases, and among the ones that had information $72 \%$ (49/68) were not vaccinated. In the post-accident prophylaxis, 75 (54.8\%) cases received the vaccine, and the homologous or heterologous serum. In 137 cases, only 1 was not hospitalized. As of the case evolution $66.4 \%$ were cured of the infection and $20.4 \%$ perished because of tetanus. The lack of information about de disease's closure in $11.6 \%$ of the cases draws attention (Table 2).

From 137 analyzed tetanus cases in this study, 119 (86.9\%) participated in the analysis of association of death with possible explaining factors, the 28 cases that evolved to death related to tetanus, and 91 cured cases.

In the bivariate analysis, was observed that the variables age and gender were related to death by tetanus, being evidenced that the patients older than 60 years old and part of the female gender had a higher probability to die. The cause of the infection also was associated to death, observing that the patients had a higher probability of dying when the transmission of Clostridium tetani was by other causes and had a borderline association when compared with the cases caused by excoriation and laceration. Unvaccinated patients had a higher chance to die, however with no statistic significance $(p=0,070)$. Among the symptoms presented in the moment of hospitalization, neck stiffness was the only symptomatic condition associated, with statistic significance, to death (Table 3)
Table 2. Accident related characteristics, from accidental tetanus confirmed cases $(\mathrm{N}=137)$ in Pernambuco, Brazil, 2007 to 2015.

\begin{tabular}{|c|c|c|}
\hline Domains/Facets & n & $\%$ \\
\hline \multicolumn{3}{|l|}{ Cause } \\
\hline Perfuration & 63 & 46.0 \\
\hline Laceration & 16 & 11.7 \\
\hline Excoriation & 15 & 11.0 \\
\hline Burn & 8 & 5.8 \\
\hline Surgical wound & 3 & 2.2 \\
\hline Others & 24 & 17.5 \\
\hline Without information & 8 & 5.8 \\
\hline \multicolumn{3}{|l|}{ Injurie Local } \\
\hline MMII & 90 & 65.7 \\
\hline MMSS & 24 & 17.5 \\
\hline Body & 2 & 1.5 \\
\hline Head/Neck & 6 & 4.4 \\
\hline Oral cavity & 5 & 3.6 \\
\hline Not informed & 10 & 7.3 \\
\hline \multicolumn{3}{|l|}{ Vaccine Situation } \\
\hline Vaccined & 19 & 13.8 \\
\hline Not vaccined & 49 & 43.1 \\
\hline Not informed & 49 & 43.1 \\
\hline \multicolumn{3}{|l|}{ Case Evolution } \\
\hline Cure & 91 & 66.4 \\
\hline Death by tetanus & 28 & 20.4 \\
\hline Death by other reasons & 2 & 1.5 \\
\hline Not informed & 16 & 11.7 \\
\hline
\end{tabular}

Considering the multivariate analysis, adjusting possible confusing variables, the women presented showed 3.46 times more chance to die; such and having other causes as gateway to the tetanus's etiologic agent made the chance of dying go up to 3.81 times and having neck stiffness as a symptom increased in 3.19 times the chance to die. It is observed that the prophylaxis variables and the symptom are predictors' variables to the severity of the case and not properly the reason that led to death (Table 4). 
Table 3. Association of researched factors and death, from accidental tetanus cases confirmed in Pernambuco, Brazil, 2007 to 2015.

\begin{tabular}{|c|c|c|c|c|c|c|}
\hline \multirow{2}{*}{ Variables } & \multicolumn{2}{|c|}{ Death $(n=28)$} & \multicolumn{2}{|c|}{ Cure(n = 91) } & \multirow{2}{*}{ OR (95\%) } & \multirow{2}{*}{ p-valor } \\
\hline & N & $\%$ & N & $\%$ & & \\
\hline \multicolumn{7}{|l|}{ Age Range } \\
\hline Less than 60 years old & 17 & 18.7 & 74 & 81.3 & 1.0 & - \\
\hline 60 years old and older & 11 & 39.3 & 17 & 60.7 & $2.82(1.12-7.09)$ & $0.028^{a}$ \\
\hline \multicolumn{7}{|l|}{ Sex } \\
\hline Male & 20 & 19.6 & 82 & 80.4 & 1.0 & - \\
\hline Female & 8 & 47.1 & 9 & 52.9 & $3.64(1.25-10.6)$ & $0.018^{a}$ \\
\hline \multicolumn{7}{|l|}{ Residence zone } \\
\hline Urban/Periurban & 24 & 23.1 & 80 & 76.9 & 1.0 & - \\
\hline Rural & 3 & 25.0 & 9 & 75.0 & $1.11(0.28-4.43)$ & 0.881 \\
\hline \multicolumn{7}{|l|}{ Cause } \\
\hline Perfuration & 7 & 13.0 & 47 & 87.0 & 1.0 & - \\
\hline Excoriation/Laceration & 8 & 28.6 & 20 & 71.4 & $2.69(0.86-8.40)$ & 0.090 \\
\hline Others & 11 & 36.7 & 19 & 63.3 & $3.89(1.31-11.5)$ & $0.014^{a}$ \\
\hline \multicolumn{7}{|l|}{ Injurie Local } \\
\hline MMII & 16 & 20.5 & 62 & 79.5 & 1.0 & - \\
\hline MMSS & 6 & 28.6 & 15 & 71.4 & $1.55(0.52-4.63)$ & 0.433 \\
\hline Other & 4 & 33.3 & 8 & 66.7 & $1.93(0.52-7.25)$ & 0.326 \\
\hline \multicolumn{7}{|l|}{ Vaccine Situation } \\
\hline Vaccinated & 1 & 5.6 & 17 & 94.4 & 1.0 & - \\
\hline Unvaccinated & 16 & 29.1 & 39 & 70.9 & $6.97(0.85-56.9)$ & 0.070 \\
\hline No information & 11 & 23.9 & 35 & 76.1 & $5.34(0.63-44.8)$ & 0.123 \\
\hline \multicolumn{7}{|l|}{ Symptoms } \\
\hline Trismus & 26 & 26.0 & 74 & 74.0 & $2.98(0.65-13.8)$ & 0.162 \\
\hline Spams & 22 & 27.8 & 57 & 72,1 & $2.00(0.73-5.43)$ & 0.177 \\
\hline Neck Stiffness & 17 & 32.7 & 35 & 97.3 & $2.86(1.14-7.13)$ & $0.024 a$ \\
\hline Member Stiffness & 12 & 24.5 & 37 & 75.5 & $1.17(0.48-2.87)$ & 0.727 \\
\hline Abdominal Stiffness & 8 & 19.0 & 34 & 81.0 & $0.75(0.29-1.92)$ & 0.545 \\
\hline Risus sardonicus & 3 & 15.0 & 17 & 85.0 & $0.56(0.15-2.09)$ & 0.391 \\
\hline Opisthotonus & 6 & 37.5 & 10 & 62.5 & $2.37(0.76-7.33)$ & 0.135 \\
\hline Others & 11 & 18.3 & 49 & 71.7 & $0.59(0.23-1.46)$ & 0.254 \\
\hline
\end{tabular}

Statistic significant associations $(p<0.005)$ 
Table 4. Multivariate analysis to the association of serched factors and death, in cases of accidental tetanus in Pernambuco, Brazil, 2007 to 2015.

\begin{tabular}{|c|c|c|}
\hline Variables & OR (95\%) & p-valor \\
\hline \multicolumn{3}{|l|}{ Gender } \\
\hline Male & 1.0 & - \\
\hline Female & $3.46(0.99-12.1)$ & 0.051 \\
\hline \multicolumn{3}{|l|}{ Cause } \\
\hline Perfuration & 1.0 & - \\
\hline Excoriation/Laceration & $1.52(0.43-5.33)$ & 0.509 \\
\hline Others & $3.86(1.13-13.1)$ & $0.031^{a}$ \\
\hline \multicolumn{3}{|l|}{ Symptoms } \\
\hline Neck Stiffness & $3.19(1.13-9.02)$ & $0.029^{a}$ \\
\hline
\end{tabular}

\section{Discussion}

The incidence of tetanus in Pernambuco in the studied years appears to be in a declining tendency, this behavior being similar to the one that occurred in Brazil. Studies point to the Northeast region for being the responsible for having the most number of case in the country, corresponding to approximately $40 \%$ of the cases, but in this study the incidence tax of the state (1.72 cases/1 million hab.) was smaller when compared to the one described nationally, between 2000 and 2012 (2.5 cases/1 million hab.). Despite this, it is considered a high incidence rate, when compared with the incidence of developed countries $(0.10$ cases/1 million hab.), suggesting that actions of prevention and control of the disease need to be intensified $[4,7,8]$.

There was male predominance, presenting a proportion of $6: 1$. The higher exposition to the gender seemed to be a particularity common to the disease, being verified in a variety of studies, including with a proportion similar to the one found in this study. We can attribute this predominance to the fact that the men are more likely to suffer accidents and traumas, beyond that the occurrence of prevention actions in health in this population is more scarce, what boosts even more to the male gender to follow the logic of the old and inefficient form of attention to the curativist health $[9,10]$.

The most $(86.1 \%)$ of the cases resided in the urban area, contradicting the tendency of a higher proportion the rural area due to soil exposition. But this fact was observed in other studies, and the infection was even reported on domestic environment, which reinforces that the bacteria may be present in any environment [9, 11-13].

However, the impairment of the individuals in all age ranges makes the health system's difficulty in guaranteeing the satisfying vaccine coverage in all of the population appears. Among the cases 66.4\% were individuals between 20 and 60 year old, an age range economically active to the country, that when gets sick causes an economical impact due to absence in work. Beyond that, the high costs to health services need to be considered, after and the disease have a severe nature and in most cases require internment in Intensive Care Unit (ICU) with a long time of treatment and possibility of sequels [5].

It is highlighted the representation of elderly among the confirmed cases of tetanus (1/4), that shows the disease's aging process in the State, as described in other locals. This occurs due to the decreasing levels of tetanus protecting antibodies added to the fact that the immunologic response is reduced, as showed in a study, to test the immunity against the disease in this age range, which verified that $94 \%$ of the elderly people showed susceptibility to tetanus and that a single dose of the vaccine wasn't able to full and immunize those individuals. Even though the vaccination against tetanus in people older than 60 years is regulated by the National Immunization Program, since 1999, 
data show that this is a group still affected by the disease $[9,14,15]$.

Researches done in Brazil and in the world, found lower protective levels against the disease in elders and adults that explains the occurrence of the disease in a higher proportion in these groups. The strategies defined by the health politics priories vaccine campaign in the maternal-child scope, but when establishing the priority groups (Child and pregnant women or that plan on getting pregnant), the health managers take the risk of neglect the prevention of the not featured people, fact that has been observed with frequency by researchers [16-18].

Of all the cases, only 19 (13.8\%) had registered that received some dose of vaccine, 16 received a single dose, two receiving two doses and only one individual, 39 years old, received three doses and a reinforcement. However, the date of the last vaccine wasn't registered which made impossible the definition of regularity in the vaccine situation of this case in the moment of the infection. Concluding that, with exception of this case, all with this information available had an irregular vaccine situation.

In this study, a high percentage of individuals $(43.1 \%)$ had registered the vaccine situation as ignored, which difficult the analysis. However, it is possible that the lack of information comes from the individual's lack of knowledge, because is not uncommon that adults and elders don't consider the information relevant and don't preserve the vaccine registration.

A study done in Canada showed that a considerable part of the adults believe that vaccines are more important to the children and $30 \%$ of the interviewed couldn't inform the vaccine situation. In this study, it also evidenced that more than half of the health professionals related difficulty in staying updated with the vaccine recommendations. However, other factors that may have been related to the low vaccine coverage among the adults are the absence of regular consults to the health service, the lack of recommendation and offer of the vaccine by the professionals and trust in the vaccine by the individual [19].

The actual challenge is to guarantee the efficacy of the vaccine programs to the population regardless of gender and age range. Some strategies may be considered as more important just like continuous actions of health awareness education to the population, training of professionals regarding the theme and guarantying the infrastructure of the services to make the offer of immunization happen in an opportune way, in each contact of the individual with the net care of health [4].

The most frequent type of injury was perforation (46\%) and the local that it occurred with the highest proportion were the lower limbs, both the information matches with the registered in other locals. In $7.3 \%$ it was not indentified the focus of the infection. A cautious anamnesis towards the suspicion of the disease may help in the identification of the bacteria doorway, because minor injuries are not noticed or are cured quickly [20].

In the datas registration, only $23.4 \%$ received the vaccine as post-wound prophylaxis, contradicting the MS recommendations which affirms that even in minimum risks wounds for tetanus, the vaccine must be applied in all that have the vaccine situation uncertain or have registered less than three doses, situation found in 136/137 o cases analyzed. Inadequacies in the realization of the prophylactic measures were related previously in the United States [4].

It is important to highlight that even with the possibility and even with the recommendation in some cases to realize the post-wound prophylaxis using simultaneously the passive immunization (immunoglobulin or anti tetanus serum) and the active immunization (vaccine) the Surveillance System of tetanus's notifying note impossibility the marking of more than one option in this item, what may have influenced this result. Added to the fact that the same item could also be marked according to the specific treatment used, without even separa- 
ting the realized measures done post wound and before the diagnosis from the ones done after the diagnosis. This may have been considered a true barrier in the investigation of the adequacy of the therapeutic management [4].

In $10.2 \%$ (14) of the cases, no prophylactic/therapeutic measures were realized according to the collected data, although they were hospitalized.

The most common symptoms were trismus, spasms and neck stiffness associated with or not with the others. These findings are in conformity with the variety of studies done related to accidental tetanus. To a precocious diagnosis, it is indispensable that the health professional is aware of the possible signs of the disease [21].

Only one case was not hospitalized, but received the anti tetanus serum application and evolved to cure. It is recommendable that the emergency services adopt in the attendance routine one of the diverse classification of the severity of accidental tetanus described in the literature. The internment in ICU, also as the pattern in the care of patients with tetanus, reduced the lethality in some locals, including the state of Pernambuco $[5,22]$.

In 1997, it was described that due to the implantation of specialized ICU to the tetanus patients with tetanus in Pernambuco, there was a reduction of lethality exciding from $35 \%(1981-1996)$ to $12.6 \%$ (1998-2004), reaching the average percentage of the developed countries (between 10\% and 17\%). However, in this study, the average lethality found was of $20.4 \%$, with a maximum in 2015 , when it presented $40 \%$. It is necessary a better investigation in the reasons that may be influencing the increase in mortality in this group [5].

The highest investments to the reduction of lethality are centered in hospitalization, but it is necessary a set of actions to reach the expected standard, because the effectiveness of the treatment is, among other factors, directly related to the precocious diagnosis and a qualified assistance.
Individuals older than 60 years presented a lethality rate of $39.3 \%$, and according to the bivariate analysis, presented a higher chance of dying by tetanus. The elderly people have a minor immunologic response and/or presents frequently co morbidities. This age group was already identified as having a greater risk of dying, by other authors. However, after the multivariate analysis, adjusting the possible confusing variables, this variable didn't remain to the end of the analysis [5, 14].

The association of neck stiffness with lethality is probably due to an occurrence of severe cases, therefore contributing to the greater chance of death, what confirms this as a sign of poor prognosis. Already the individuals who did not receive any prophylactic measures had almost 4 times more chance of die, reinforcing the importance of emergency services to provide prophylaxis for all injuries which have the possibility of exposure to the disease, because ensure that individuals receive some type of immunity after exposure, can reduce their severity by conferring them some kind of immunity [21, 23].

The highest female lethality was previously observed, women were more likely to die than men, but the association was only found in the univariate analysis. The higher lethality in females may be related to the fact that $62.5 \%$ of the women were elderly. In addition, there is the necessity to consider the number of women ( $n=8$ ) who were evaluated. Probably the sample size in our study was not enough to explain this in the multivariate analysis, as suggested by the confidence interval.

Another barrier is the difficulty in identifying prophylactic measures separately from treatment, since the completion does not allow segregation. Thus, this study points out the need to improve the sheet of accidental tetanus research in the Surveillance System of tetanus registry, since the information contained in the information system can support the improvement of public health policies in Brazil. 
The permanence of high incidence of accidental tetanus is detachable, because it is a vaccinepreventable disease. This study points out the need for greater investments in the prevention of disease, as well vaccine coverage in the application of prophylaxis. These are simple measures and have relatively low cost when compared to ICU hospitalizations that result from the disease and directly influence tetanus morbidity and mortality.

Special attention shall be given to cases that present nape stiffness as a symptom, since these groups present a greater chance of progressing to death. Despite of the guarantee of hospitalization with adequate care, there was an increase in tetanus lethality, what suggests that more should be developed to investigate what may have influenced this change.

\section{References}

1. Arango S.D., Betancur F.L.A., Aguirre M.C., Quevedo V.A. Tétanos: ¡Todavía un problema de salud pública!. Iatreia. 2008 Apr./June; 21(2): 186-198.

2. Organização Mundial da Saúde. Vaccine-preventable diseases: monitoring system. 2010 global summary.

3. Brasil. Ministério da Saúde. Secretaria de Vigilância em Saúde. Guia de Vigilância em Saúde. Brasília: Ministério da Saúde, 2014. 812 p. Available from: www.saude.gov.br/bvs

4. Centers for Disease Control and Prevention. Tetanus SurveillanceUnited States, 2001-2008. Morbidity and Mortality Weekly Report (MMWR) 2011; 60.

5. Gouveia P.A.C., Silva C.E.F., Miranda-Filho D.B., Bernardino S.N., Escarião A.G., Ximenes R.A.A. Tendência temporal do tétano acidental no período de 1981 a 2004 em Pernambuco com avaliação do impacto da assistência em unidade de terapia intensiva sobre a letalidade. Rev. Soc. Bras. Med. Trop. 2009 Fev; 42(1): 54-57.

6. Armijo M.J., Soto-Aguilar B.F., Brito A.C. Tétanos generalizado: caso clínico y revisión del tema. Rev. chil. neuro-psiquiatr. 2012 Dic.; 50(4): 229-233.

7. Brasil. Ministério da Saúde. Secretaria de Vigilância em Saúde. Departamento de Análise de Situação em Saúde. Saúde Brasil 2012: uma análise da situação de saúde e dos 40 anos do Programa Nacional de Imunizações. Brasília: Ministério da Saúde; 2013. 536.
8. Maeda S.T., Gryschek A.L.F.L.P., Duarte Y.A.O., Tomo T.T.. Tétano acidental no município de São Paulo: da perspectiva epidemiológica à dimensão individual no processo de atendimento. Saúde Coletiva. 2009; 6(31): 135-140.

9. Neves F.F., Faiolla R.C.L., Napoli E,M.G., Lima G.M.N., Muniz R.Z.A., Pazin-Filho A. Perfil clínico-epidemiológico dos casos de tétano acidental ocorridos em Ribeirão Preto, Estado de São Paulo, no período de 1990 a 2009. Rev. Soc. Bras. Med. Trop. 2011 Aug; 44(4): 481-485.

10. Chalya, P. L., Mabula, J. B., Dass, R. M., Mbelenge, N., Mshana, S. E., Gilyoma, J. M. Ten-year experiences with Tetanus at a Tertiary hospital in Northwestern Tanzania: A retrospective review of 102 cases. World Journal of Emergency Surgery. 2011 Jul 8; 6: 20.

11. Vieira L.J., Santos L.M.. Aspectos epidemiológicos do tétano acidental no Estado de Minas Gerais, Brasil, 2001-2006. Epidemiol. Serv. Saúde. 2009 Dez; 18(4): 357-364.

12. Feijão A.R., Brito D.M.S., Peres D.A., Galvão M.T.G. Tétano acidental no Estado do Ceará, entre 2002 e 2005. Rev. Soc. Bras. Med. Trop. 2007 Aug; 40(4): 426-430.

13. Pagliuca L. Marlena F., Feitoza A.R., Feijão A.R.. Tétano na população geriátrica: problemática da saúde coletiva?. Rev. Latino-Am. Enfermagem. 2001 Nov; 9(6): 69-75.

14. Vieira L.J., Santos G.P.. Tétano acidental no idoso: situação em Minas Gerais. Rev APS. 2011 abr/jun; 14(2): 177-184

15. Weckx L.Y., Divino-Goes K., Lihama D.M., Carraro E., Bellei N., Granato C.F., et al. Effect of a single tetanus-diphtheria vaccine dose on the immunity of elderly people in São Paulo, Brazil. Brazilian Journal of Medical and Biological Research. 2006 Apr; 39(4): 519-523.

16. Rapisarda V., Bracci M., Nunnari G., Ferrante M., Ledda C. Tetanus immunity in construction workers in Italy. Occup Med (Lond). 2014; 64(3): 217-219.

17. Karabay O., Ozkardes F., Tamer A., Karaarslan K. Tetanus immunity in nursing home residents of Bolu, Turkey. BMC Public Health 2005 Jan 12; 5: 5 .

18. Divino-Goes K.G., Moraes-Pinto M.I. de, Dinelli M.I.S., Casagrande S.T., Bonetti T.C.S., Andrade P.R. et al . Prevalence of diphtheria and tetanus antibodies and circulation of Corynebacterium diphtheriae in São Paulo, Brazil. Braz J Med Biol Res. 2007 Dec; 40(12): 1681-1687.

19. MacDougall D.M., Halperin B.A., MacKinnon-Cameron D., Li L., McNeil S.A., Langley J.M., et al. The challenge of vaccinating adults: attitudes and beliefs of the Canadian public and healthcare providers. BMJ Open. 2015 Sep 29; 5 (9): e009062. 
20. De Mattos A.C., Júnior C.G., Fuentefria A. Tetanus epidemiology in Santa Catarina, Brazil from 1998 to 2008. Infectio. 2010; 14(2): 112-119.

21. Miranda-Filho D.B., Ximenes R.A.A., Bernardino S.N., Escarião A.G.. Identification of risk factors for death from tetanus in Pernambuco, Brazil: a case-control study. Rev. Inst. Med. trop. S. Paulo. 2000 Dec; 42(6): 333-339.

22. Brauner J., Vieira R.S., Bleck T. Changes in severe accidental tetanus mortality in the ICU during two decades in Brazil. Intensive Care Med. 2002 July; 28(7): 930-935.

23. Saltoglu N., Tasova Y., Midikli D., Burgut R., Dündar I.H. Prognostic factors affecting deaths from adult tetanus. Clinical Microbiology and Infection. 2004 March;10(3): 229- 233.

Publish in International Archives of Medicine

International Archives of Medicine is an open access journal publishing articles encompassing all aspects of medical science and clinical practice. IAM is considered a megajournal with independent sections on all areas of medicine. IAM is a really international journal with authors and board members from all around the world. 